https://doi.org/10.48009/1_iis_2010_364-371

\title{
BUSINESS PROCESS RE DESIGN IN EDUCATIONAL INSTITUTES IN MIDDLE EASTERN COUNTRIES: CASE STUDY
}

\author{
Lila Rajabion, Prince Mohammad Bin Fahd University \\ Fida Alsughair, Prince Mohammad Bin Fahd University \\ Arwa Aldossary, Prince Mohammad Bin Fahd University \\ Seba Almaghlouth, Prince Mohammad Bin Fahd University \\ Noora Abunayan, Prince Mohammad Bin Fahd University
}

\begin{abstract}
Business process re-engineering (BPR) is the main way in which organizations become more efficient and modernize. It transforms an organization in many different ways and can directly have an impact on the performance of an organization.

Even though many Saudi technical and vocational training agencies are employing e-Learning strategies, Saudi schools and educational systems are still relying on paperwork and functional areas for operations. Furthermore, they have been trying to improve the system by only relying on new technology to just automate operations, without redesigning the process.

This case study attempts to apply business process redesign tools into the functional operations and management processes at a school in Saudi Arabia. The National Educational Girls School (NEGS) in AlKhobar is one of many organizations that is trying to develop a new business process in to its operations.
\end{abstract}

The purpose of the study is to present a working business process redesign model, which identifies the problems with the current management system and presents a reengineering solution that can be used as a reference in similar projects.

The methodology that this study proposes is based on three step process: The primary step is to study an outline of the management structure for NEGS and their basic functions. The Second step is to present a model of NEGS current business processes.. The final step is to present a redesigned model of NEGS management and educational processes, eliminating all redundancies and excess resources, employing technical solutions and redesigning un-integrated entities into network. Finally develop an integrate model for all the processes that can be used as a reference for other schools in Middle Eastern countries.
Keywords: BPR, School, Integrated system, developing countries, educational system

\section{INTRODUCTION}

Business Process Redesign is "the analysis and design of workflows and processes within and between organizations" (Davenport \& Short 1990). Teng et al. (1994) define BPR as "the critical analysis and radical redesign of existing business processes to achieve breakthrough improvements in performance measures."

For businesses to achieve impressive improvements in productivity, production time and quality, business process redesign is applied to radically redesign the core business processes which will lead to desired results. Here, companies think from the scratch of the processes which can deliver more value to its customers. Here, customer needs are taken care of by emphasizing on adopting a new value system. For putting business process redesign, companies have to eliminate layers of hierarchy and unproductive activities. The first step of the company should be to form cross functional teams and next step should be to improve data dissemination and improved decision making by using technology. (Business Process Reengineering)

The main challenge that Saudi Arabia faces at school is that the curriculum of studies includes $75 \%$ of studies in religion. Priority is not given to subjects like math, science and knowledge of other cultures and world outside. More efforts are required to be put in developing brains of people and investing in humans. The King of Saudi, king Abdullah is of the same opinion and has invested more than SR 9 billion for new education projects and an amount of more than SR 3 billion has been put aside for the training and development of teachers. Saudi schools are still following the traditional approach of paperwork and other functional areas of operation and have still not become familiar with the modern technology in 
education. More efforts are required to automate systems and use of technology. (Jawhar)

This study is mainly carried out so that we can identify the current problems of the management style and design a reengineering solution for the school which can be adopted as a model by the other schools of Saudi Arabia. To make this possible the first thing that needs to be done is to draw the management structure of the Alriyadh School and its basic functions. The next step is to present the model of the functional process of the school. And the last step would be to present a redesigned model for the Alriyadh School which will eliminate all redundancies and excess resources and employ technical techniques. The ultimate objective would be to come up with a model that will be used as a reference by all the other schools in the Middle Eastern countries.

\section{LITERATURE REVIEW}

According to Michael Hammer and Champy, Business process reengineering is the analysis and redesign of workflows within and between enterprises as mentioned in their bestselling book, "Reengineering the Corporation". According to the authors, information technology was the key enabler to bring the radical change that was required for the redesign and reorganization of the enterprise for lowering the cost and improving the efficiency and quality of service. To streamline the processes of work and to achieve a significant level of improvement in the performance and quality, time management and cost, the authors have provided 7 guiding principles:

1. Organize your activities around outcomes and not tasks.

2. Prioritizing the processes in order of their redesigned urgency after its proper identification. 3 . The real work to be integrated well with the information processing work.

4. Dispersed resources should be centralized.

5. Linking the parallel activities in the workflow.

6. Taking prompt decisions and building a control system.
7. Capture information once and at the source. (business process reengineering, 2009)

This report is a research on the business process redesign of a School in Riyadh, Alriyadh School. The current processes are studied and a redesigned model is suggested for the process and data flow.

In Saudi Arabia, education system consists of 3 levels:

1. Pre elementary

2. Elementary

3. Intermediate

It is a standard system for education followed throughout the region. Education till Elementary level is compulsory for boys as well as girls, though schools for both are different. There are virtually no co education schools in Saudi Arabia, because of their conservative and orthodox mentality. However there are many International schools recently coming up in the country because of increase in migration to this country. With people coming to this country, the demand for better education has been increasing to stay at par with the world education system. No more the students learn from books only. The sources of education has been changing from books to other sources like practical examples, more live experiments, internet and also students are sent to foreign universities by their schools and colleges as a part of their education programmes. As the education system is interdependent on other human systems, it is not possible for it to perform in isolation.

There is a strong need to change the traditional system of pass/fail to a continuous and comprehensive evaluation system which will help to identify and nurture the hidden skills and talents of students. It is important to change the system from Same Thinking Order to High Order Thinking System which will help the entire education system to undergo a total change. (Singh, 2008)

If we compare the education system at Alriyadh School to other International schools, the level of education is found to be far below the average level. This is due to the way of imparting education been adopted by the school is far primitive than most other schools. In today's modern time, schools have adopted to more interactive learning methods than sticking strictly to textbooks. Technology and computers have played a vital role in imparting useful education. Many people are apprehensive of the harmful effects of technology in class for 
educating. There are doubts on the ability of students to relate to other humans if teaching is done through computers. Doubts are also on the ability to learn from any other source than computers. There are apprehensions of children finding inappropriate material on internet, etc. But there had also been apprehensions during the invention of radio, television, satellite, printing press, etc. All these sources could have been put to inappropriate use, but all these sources led to human development and better spread of knowledge and development. When technology is used appropriately, with interaction and guidance, it becomes the best source of development of higher order thinking skills. If technology is used inappropriately in the classroom, it will only result in bringing about the old techniques of learning. Students will stick to computers and it will result in the same outcome as it used to from learning from workbooks. Instead, teachers should make good use of computers and multimedia to produce colourful lectures which are more interesting and stimulating to the students. (Technology in Education)

It is very important for Alriyadh to undergo business process redesign to keep up with the changing demands of today for a better education system. Worldwide the education system has been modernizing with maximum technology usage and minimum human interventions. It is also observed that children become more analytical and skillful by making use of such technology than learning from traditional book approach. But to ensure that Alriyadh School adopts such technological change, it is important for the school to have proper infrastructure for such technology. Not only the content of the curriculum has to change, but also the way the management of school is carried out has to be changed. The intention behind building a proper infrastructure for technology is to make school complacent with capabilities to utilize telecommunication network featuring video, instructional TV, data, phone and intercom system. Security system of school should also be supported by such technology infrastructure. Other infrastructure related to technology in school would also include the heating and cooling systems, power distribution to workstations of students and faculties as well as for other equipments. The infrastructure should have the capability to support latest communication tools and gadgets. Also there should be reliable system for sharing information which should be centralized and handled by a local administrator. Information sharing devices would include telephone, fax, computer machines, VCR, other electronically transmitted devices.

\section{(PLANNING THE TECHNOLOGY INFRASTRUCTURE: GENERAL REQUIREMENTS)}

In the case of Alriyadh, it is required to bring about a new model of education system which can be adopted and for which some changes are required to be made in the current processes being followed at the school. This change is called Education Process Reengineering, where efforts would be made to identify the current process of Alriyadh's management which needs correction and redesigning a new model which is technologically much advanced.

\section{RESEARCH METHODOLOGY}

\section{INTERVIEW:}

For finding out the processes being followed in Alriyadh school, interviews were carried out with the board of representatives formed for Academic function and department heads of all the other departments like administration and Corporate Liaison. Basic questions were asked in the interview to understand the processes of each department, how the department functions, what technology is currently being applied for functions, what kind of work is done manually, the process flow chart, etc. Each question was answered in detail by the staff and heads very patiently.

\section{OBSERVATION:}

From the interview it has been observed that administration function has lot of responsibilities in the school. And as a result of manual processes and duplication of work between administration and accounts, they have deployed a huge staff to carry out the responsibilities. Moreover the function is carried out in a very traditional manner, with minimal technological interference. As a result of which the processes are also slow and lagging far behind the modern processes applied at other International school in Riyadh and Saudi Arabia.

\section{METHODOLOGY}

Current Management Processes at Alriyadh School:

- The current admission system is through filling up forms by aspiring students/parents of students and submitting them at the administration office during specified timing along with certain amount of fees. 
- Submission of photocopy of documents along with the form for admission.

- Visiting the schools again to know the status of admission.

- Once the child is admitted, the requirements of uniform and books are given to them by their class teacher in the form of a list of items required. These things are to be procured within a specified time by the students.

- The school collects fees on quarterly basis the students are given a fee card for the documentation of fees paid. Fees are required to be paid in cash by the students at the accounts office.

- The class still follows the traditional approach of marking attendance of students by calling out the roll numbers of the students.

- Class is taught through the traditional approach of using blackboards and chalks for writing.

Proposed Management Processes at Alriyadh School:

- World over now the schools have made the admission process online, where the parents can acquire admission forms from the website of the school, fill in the necessary details and submit the form online along with the fees demanded through credit cards. This will minimize the hassles of the parents as well as of the school's administration of handling such huge crowd at a time. Moreover, this also solves the problem of maintaining physical files of physical admission forms and thus saves space in the administration office. Online forms can easily be saved on computers.

- There should be provision on the website of the school to attach the photocopies of the documents required by the school for admission. Such documents can be scanned and attached and sent to the school online. This will again solve the problem of utilizing physical space and the hassles of maintaining physical records of aspiring students. (Prince-Cohen)
- The status of admission should be displayed online by the school's administration. There should be a list displayed showing the waiting number of the students who has applied for admission. Exact date and time should be mentioned for the round of personal interview, so that the parents do not have to bother about finding out with the school's administration by calling them or visiting them often and also the administration is relieved from answering such calls and attending such queries.

- Once the child is admitted to the school, it becomes the duty of the school to make students aware of the rules and regulations, school timings, other requirements. For students from standard KG till $4^{\text {th }}$, the school should have the system of sending emails to their parents regarding the requirements such as uniforms, books, date of fee payments, schedule of the activities planned in the year, list of holidays, etc. There should not be any loose paper handed to the child as there are chances of that been destroyed accidentally or misplaced by the small child. Moreover sending email to parents is easy as it goes in one click which saves lot of time and energy of both, the school's administration as well as of parents. (Bratina, Bratina, \& Bratina)

- For students from $5^{\text {th }}$ standard till $12^{\text {th }}$ standard, they get their individual workstations, where in there are required to mark their presence at the starting of the day, which saves the teachers from the hassles of taking oral call outs for attendance. Also it is a more reliable method. Each student is given a $\log$ in ID and password which is confidential and subject to change in every 15 days. Moreover the id and password of a particular student can be accessed on his respective system only. This makes it a fool proof method for attendance. Class work is also displayed on the individual systems of the students, so that they can get started with their work. Use of internet is encouraged for research work which makes students more conversant with the technology which is very important in today's time. (Kumar) 
Instead of teaching through only textbooks and on blackboards, usage of interactive learning should be encouraged. Learning also happens through showing video clippings on related topics. It is scientifically proven that visuals have more impact than audio in remembering and understanding concepts. Lectures should be taken on LCD projector screens instead of traditional blackboards. Also lectures can be arranged by guest faculties through video conferencing and make it more interactive where students can present their doubts and get solution from the faculty through video conferencing. This helps in overall development of a child. (Dede, 1995)

ANALYSIS

Organizational Structure of Alriyadh School

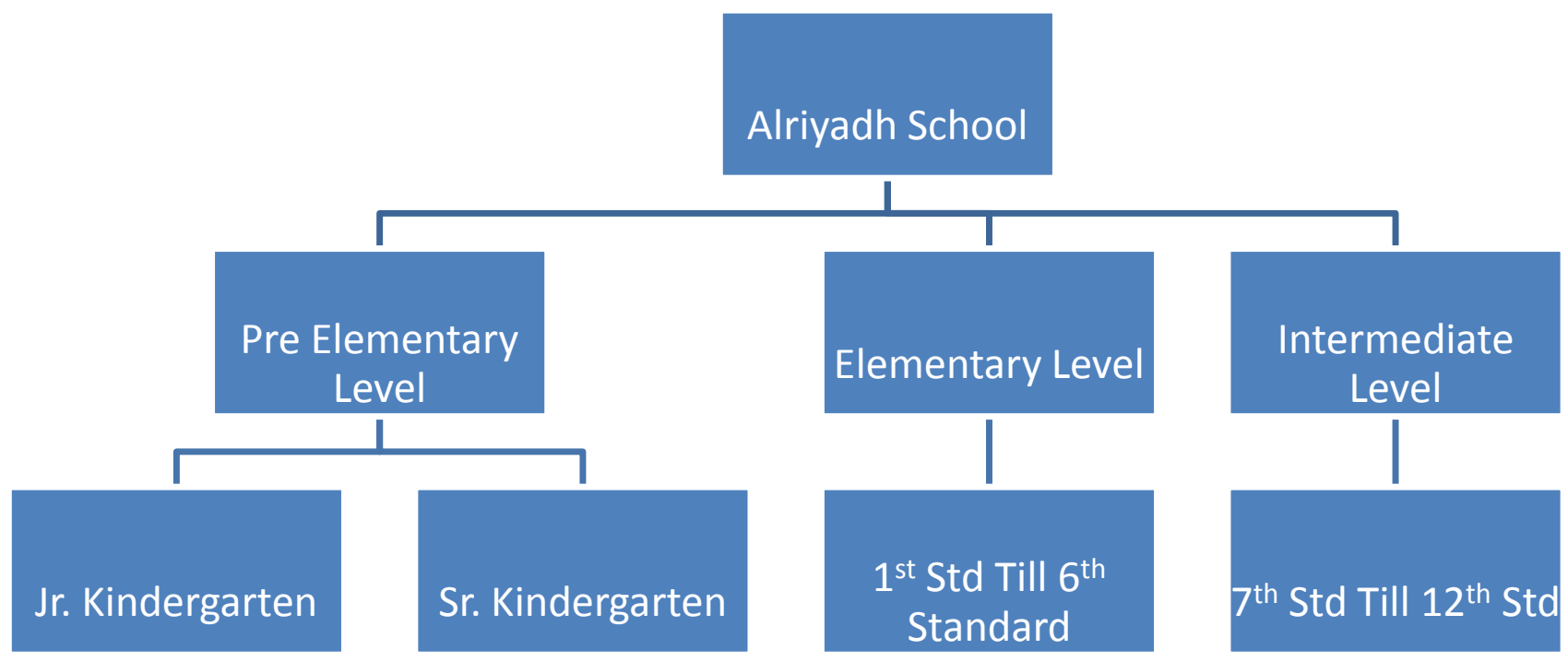

Alriyadh School has different functions, like Academic function, Administrative function, Accounting function and Corporate Liaison function. Let us see the management of business processes in all these functions.

\section{How is current Academic function handled?}

Alriyadh has formed a board which consists of teachers and state board representatives which decide upon the curriculum at different levels. They also take decisions on changes to be made in fee structure, amendments in sports activities, extra curricular activities, etc. This board meets at the end of each year and discussions are carried out, suggestions are put forward and then, the head of the board takes a call on any changes to be made. Same changes are then agreed upon by all and published in the newsletter of the school. Each year's changes are then fed into the computer system by the administration department of the school for future records. 


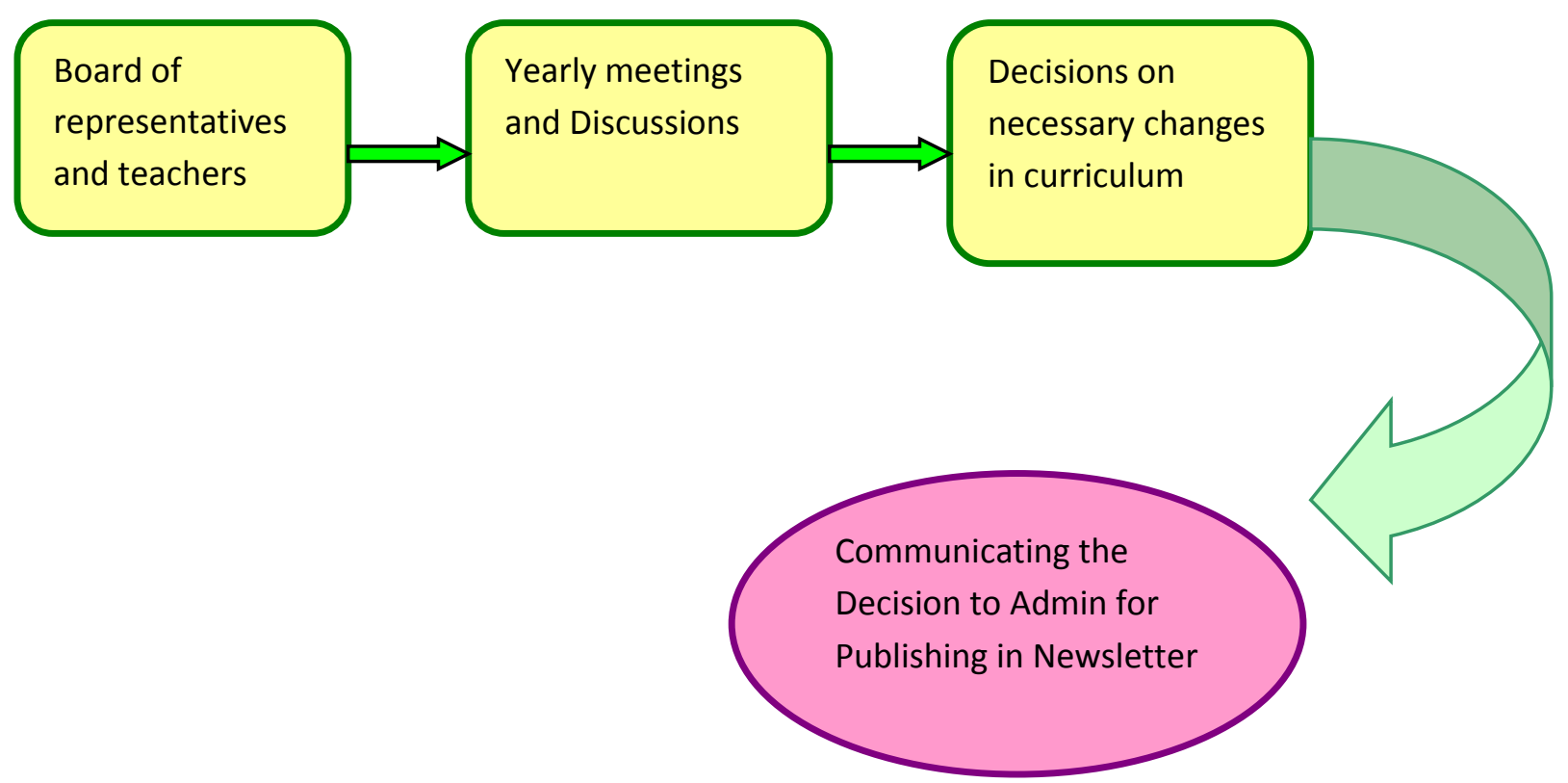

\section{Administration Function}

Administration department is responsible for number of things like, taking care of admission, issuing forms, collecting filled forms along with other required documents, fee amount, feeding the same data in computers, allocating the students their respective divisions, preparing registers, publishing the newsletter, taking care of the water and electricity of school, transportation for students and staff, taking care of the requirement of boarding of students and any other contingency that may arise in the process. Most of the work done by them is manually and therefore this department has maximum staff.

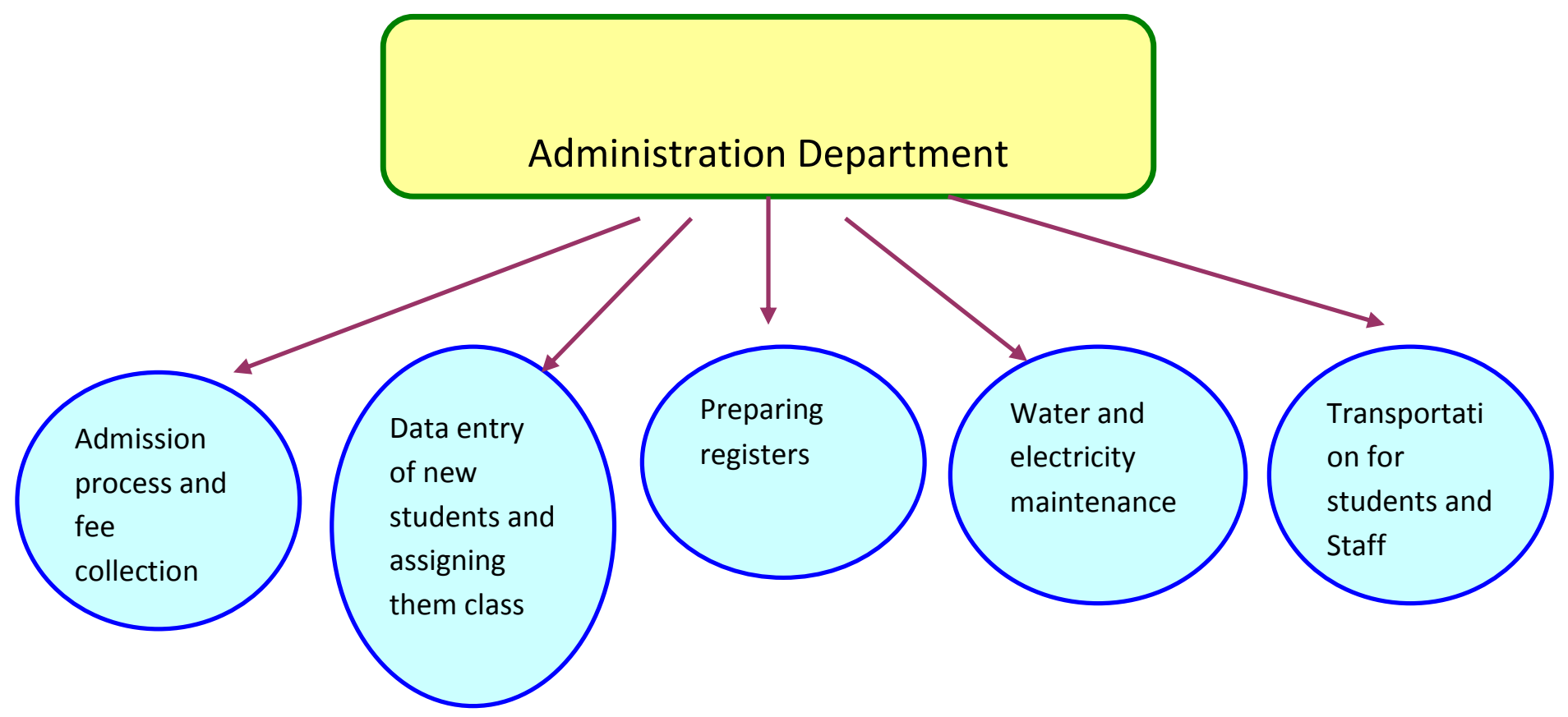




\section{Proposed Processes (Process Redesign)}

It is seen from the above analysis of the current processes of Alriyadh School that most of the things are manual with minimum intervention of any technology (computers). It is very important for Alriyadh School to change its business processes to more technologically advanced processes. Below mentioned is the proposed redesigned model for Alriyadh School.

No matter what the school's educational philosophies are, there are some general requirements that holds true. Technology infrastructure of school should be such that it is able to respond to the changing demography of students, curriculum changes and technological advancement. Certain general principles to be remembered are:

1. Design should be driven by sound curriculum and not technology, as technology is just a tool.

2. There is no fixed educational solution that is suitable for all.

3. Flexible school environment to accommodate future technological changes.

\section{(PLANNING THE TECHNOLOGY INFRASTRUCTURE: GENERAL REQUIREMENTS)}

While designing the technological infrastructure for Alriyadh, things to be kept in mind:

- Proper cable networking between buildings to eliminate future chances of accidents and breakdowns due to load shedding.

- Proper installation of firewalls. Care has to be taken that it is installed at a place which is safe in case of fire or accidents, as it has to be installed at a school.

- Website of Alriyadh School should be built, which would enable online filling of forms for admission, facility to make payments online, submitting documents online and a $24 \times 7$ customer support to solve any queries of parents.

Process Redesign for Academic function:

- There has to be individual workstations for all participating members of the board, who would float their suggestion on the internal school network, which can be viewed by all members and can be commented upon.

- All the necessary decisions are to be floated on the internal network which can be viewed by the administration department for publishing purpose.

- This should eliminate the manual work of recording decisions in file and then feeding the data on computers.

\section{(PLANNING THE TECHNOLOGY \\ INFRASTRUCTURE: GENERAL REQUIREMENTS)}

Process Redesign for Administration function:

- Since everything is now supported by computer systems, administration department would directly get admission forms from aspiring students online, receive payments online which can directly be viewed by the accounts department and taken care of, documents are received online.

- Once the admission is given to a student, emails of the same can be floated to the parents for informing them about the school's decision.

- Now, since there is a centralized system for electricity maintenance and security system, administration department has not to be vigilant about the same. The CCTV cameras are located in principal's office, admin department, accounts department and each class. This makes the vigilance easy. The security system installed at the gate has a centralized system which takes care of any accident or theft or any other problem that may arise.

(PLANNING THE TECHNOLOGY

INFRASTRUCTURE: GENERAL REQUIREMENTS) 


\section{CONCLUSION}

By referring to the case study and analyzing the current processes at Alriyadh School, it is evident that the school still follows the same traditional system. Still the administration department follows the old tradition for admission process and preparing registers. In today's modern world where everything is done through online processes, Alriyadh has still hung to its traditional methods. These manual processes need a change. The proposed changed has been discussed in our report which will gie Alriyadh school and edge over the other schools. Our report should be able to throw some light on how the processes can be improved by using Business Process Redesign.

\section{RESEARCH LIMITATION}

The research has been carried out only through personal interviews with the department heads. As only one method is applied, the result may not be exhaustive enough to jump to a conclusion, but still, by and large the result can be trust worthy to propose a better business process redesign. The result could have been more impressive should we have included research carried out at other schools too to suggest some changes to Alriyadh School about what modern techniques could be adopted to improve the processes.

\section{RECOMMENDATIONS}

Efforts should be made in making processes simpler by eliminating manual recordings and paper work and making utmost use of technology. In today's time of high tech CCTV cameras and security system, it is advisable to adopt these technologies than sticking to traditional way of vigilance. Proper care should be taken that work is not duplicated at any point of time, like two departments doing the same job. This can be done by proper job division and clarity of job.

\section{REFERENCES}

Bratina, T., Bratina, T., \& Bratina, A. (n.d.). Listen Up!: Using Audio Files in the Curriculum. Retrieved June 7, 2010, from New Horzons: http://www.newhorizons.org/strategies/technology/br atina.htm

Business Process Reengineering. (n.d.). Retrieved June 7, 2010, from Management Tools: http://www.bain.com/management_tools/tools_busin ess_process.asp?groupcode $=2$

business process reengineering. (2009, March 11). Retrieved June 7, 2010, from Search CIO: http://searchcio.techtarget.com/sDefinition/0,,sid182_ gci536451,00.html

Dede, C. (1995, October 12). Testimony to the US Congress, House of Representatives Joint Hearing on Educational Technology in the 21st Century. Retrieved June 7, 2010, from New Horizons: http://www.newhorizons.org/strategies/technology/de de1.htm

Jawhar, S. S. (n.d.). Challenges in modernizing the Saudi education system. Retrieved June 7, 2010, from Saudi wave: http://saudiwave.com/index.php?option=com_content \&view=article \&id=694\%3Achallenges-inmodernizing-the-saudi-education-system\&Itemid $=106$

Kumar, M. (n.d.). Learning with the Internet. Retrieved June 7, 2010, from New Horizons: http://www.newhorizons.org/strategies/technology/m uthukumar.htm

PLANNING THE TECHNOLOGY INFRASTRUCTURE: GENERAL REQUIREMENTS. (n.d.). Retrieved June 7, 2010, from Tcet: http://www.tcet.unt.edu/pubs/di/05di.pdf

Prince-Cohen, N. (n.d.). Questions for Potential Online Instructors. Retrieved June 7, 2010, from New

Horizons: http://www.newhorizons.org/strategies/technology/pr ince\%20cohen.htm

Singh, V. P. (2008, may 4). CBSE aims to bring changes in traditional education system. Retrieved June 7, 2010, from Express India: http://www.expressindia.com/latest-news/cbse-aimsto-bring-changes-in-traditional-educationsystem/305182/

Technology in Education. (n.d.). Retrieved June 7, 2010, from New Horizons: http://www.newhorizons.org/strategies/technology/fr ont_tech.htm 